Tropical Journal of Pharmaceutical Research September 2021; 20 (9): 1983-1989

ISSN: $1596-5996$ (print); 1596-9827 (electronic)

(C) Pharmacotherapy Group, Faculty of Pharmacy, University of Benin, Benin City, 300001 Nigeria.

\title{
A study of the effect of combination of acupuncture and Chinese medicine (Ban Xia Xie Xin Decoction) on patients with sepsis-induced gastrointestinal dysfunction
}

\author{
Yanfei Lv ${ }^{1,2}$, Feng Dong ${ }^{3}$, Hao Hao ${ }^{3}$, Li Kong ${ }^{3 *}$ \\ ${ }^{1}$ Postdoctoral Mobile Station of Shandong University of Traditional Chinese Medicine, ${ }^{2}$ Department of Rehabilitation Medicine, \\ Shandong Provincial Hospital affiliated to Shandong First Medical University, ${ }^{3}$ Department of Emergency and Critical Care \\ Medicine, Affiliated Hospital of Shandong University of Traditional Chinese Medicine, Shandong, China
}

*For correspondence: Email: shangfuna1037@163.com

Sent for review: 6 June 2021

Revised accepted: 19 August 2021

\begin{abstract}
Purpose: To investigate the therapeutic effect of combination of acupuncture and Ban Xia Xie Xin Decoction (BXXXD) in patients with sepsis-induced gastrointestinal dysfunction.

Methods: A total of 100 patients with sepsis and gastrointestinal dysfunction admitted to our hospital from June 2019 to December 2020 were randomly assigned to a control group and a study group for a retrospective analysis. Both groups received acupuncture treatment, while BXXXD was given to the study group, in addition to acupuncture. Treatment effectiveness, incidence of adverse reactions, degree of recurrence at 1, 2 and 3 months after treatment, gastrointestinal dysfunction scores after 1 week of treatment, quality of life index (QLI) scores, frequencies of flatulence and defecation within 48 $h$, number of bowel rumblings, as well as levels of gastrin and cholecystokinin (CCK), were determined and compared between the two groups.

Results: The group with BXXXD intervention demonstrated superior treatment effectiveness, QLI scores, frequencies of flatulence and defecation within $48 \mathrm{~h}$, number of bowel rumblings, and level of gastrin than those who received only acupuncture treatment $(p<0.05)$. There was strong evidence of lower incidence of adverse reactions, recurrence at 1, 2, and 3 months after treatment; gastrointestinal dysfunction scores and CCK levels after 1 week of treatment was higher in the study group than in the control group $(p<0.05)$.

Conclusion: The combination of acupuncture and BXXXD is superior to acupuncture alone in sepsis patients with gastrointestinal dysfunction. The combination therapy produces its effect by decreasing clinical symptoms, promoting recovery of the patients, and elevating their quality of life.
\end{abstract}

Keywords: Acupuncture, Ban Xia Xie Xin Decoction, Sepsis, Gastrointestinal dysfunction, Quality of life

This is an Open Access article that uses a funding model which does not charge readers or their institutions for access and distributed under the terms of the Creative Commons Attribution License (http://creativecommons.org/licenses/by/4.0) and the Budapest Open Access Initiative (http://www.budapestopenaccessinitiative.org/read), which permit unrestricted use, distribution, and reproduction in any medium, provided the original work is properly credited.

Tropical Journal of Pharmaceutical Research is indexed by Science Citation Index (SciSearch), Scopus, International Pharmaceutical Abstract, Chemical Abstracts, Embase, Index Copernicus, EBSCO, African Index Medicus, JournalSeek, Journal Citation Reports/Science Edition, Directory of Open Access Journals (DOAJ), African Journal Online, Bioline International, Open-J-Gate and Pharmacy Abstracts

\section{INTRODUCTION}

Sepsis-induced gastrointestinal dysfunction refers to a decrease in gastrointestinal function due to sepsis in patients, resulting in indigestion, constipation, gastric aches and pains [1-3]. Sepsis is an important cause of death in intensive care unit (ICU) patients. It manifests in fever, rapid heartbeat, shortness of breath, edema, aberrantly elevated blood sugar, and 
increased levels of inflammatory factors. Other features include raised blood pressure, decreased blood oxygen saturation, abnormal liver and kidney function, aberrant gastrointestinal function, shock, unconsciousness or even death [4-6].

Sepsis is linked to gastrointestinal dysfunction. Consequently, simultaneous treatment is important for patients with sepsis and gastrointestinal dysfunction, to avoid further progression of the disease.

Chinese medicine is effective for regulation of gastrointestinal function, enhancement of gastrointestinal peristalsis, and mitigation of indigestion and constipation. Ban Xia Xie Xin Decoction (BXXXD) is a traditional Chinese herbal medicine made from pinellia, astragalus, dried ginger, and ginseng, and it is used for the treatment of acute and chronic gastroenteritis. The formula is obtained from Treatise on Febrile and Miscellaneous Diseases, and it has produced beneficial outcomes in modern clinical applications [7-9]. The present study was aimed at investigating the effect of combination of acupuncture and BXXXD on patients with sepsis and gastrointestinal dysfunction.

\section{METHODS}

\section{General patient profile}

Retrospective analysis was carried out on 100 patients with sepsis and gastrointestinal dysfunction who were admitted to Department of Emergency and Critical Care Medicine, Affiliated Hospital of Shandong University of Traditional Chinese Medicine, from June 2019 to December 2020. The patients were randomly assigned to a control group and a study group. Patients in the control group were aged 39 - 75 years, while those in the study group were in the age range of 41 - 75 years. As shown in Table 1, the two groups were comparable with regard to gender and age $(p>0.05)$. The protocol was approved by the Medical Science Research Ethics Committee of Shandong Provincial Hospital affiliated to Shandong First Medical University (approval no. 2018-101(05), and followed the international guidelines for human studies [10].

\section{Inclusion/exclusion criteria}

\section{Inclusion criteria}

Patients in the following categories were included: those who met the clinical manifestations of sepsis-induced gastrointestinal dysfunction, patients aged $\geq 18$ years, those without other organic diseases, and those with no history of drug allergy, drug abuse, or bad habits.

\section{Exclusion criteria}

Patients who had a history of digestive system diseases, those with mental disorders, and patients with malignant tumors were excluded from the study. This study was approved by the ethics committee of our hospital. All patients voluntarily participated in the study and signed an informed consent form.

\section{Treatments}

Acupuncture treatment was adopted for patients in the control group. The patients were placed in a supine position, and the skin surface at the site of the needle was pre-disinfected. Acupuncture was conducted with a $0.3 \times 40 \mathrm{~mm}$ needle on the acupoint of Zhongwan, Zusanli, Neiguan, Sanyinjiao and Taichong for $30 \mathrm{~min}$, once daily for five consecutive days.

The study group was treated with acupuncture and BXXXD, while the control group received acupuncture only.

Table 1: Patient profile (mean \pm SD)

\begin{tabular}{lcccc}
\hline Group & Study & Control & t/ $\mathbf{X}^{\mathbf{2}}$ & $\boldsymbol{P}$-value \\
\hline Gender(male/female) & $30 / 20$ & $27 / 23$ & 0.37 & 0.55 \\
Age (years) & $59.67 \pm 7.45$ & $59.10 \pm 7.77$ & 0.37 & 0.71 \\
Height $(\mathrm{cm})$ & $169.52 \pm 7.50$ & $169.97 \pm 7.53$ & 0.30 & 0.77 \\
Weight $(\mathrm{kg})$ & $72.89 \pm 8.41$ & $72.22 \pm 8.55$ & 0.40 & 0.69 \\
History of smoking & $8.73 \pm 1.28$ & $8.60 \pm 1.54$ & 0.46 & 0.65 \\
$\begin{array}{l}\text { (years) } \\
\text { History of drinking }\end{array}$ & $10.44 \pm 2.21$ & $10.30 \pm 2.38$ & 0.30 & 0.76 \\
$\begin{array}{l}\text { (years) } \\
\text { Hypertension cases }\end{array}$ & 10 & 12 & 0.23 & 0.63 \\
$\begin{array}{l}\text { Diabetes cases } \\
\text { Hyperlipidemia }\end{array}$ & 10 & 7 & 0.64 & 0.42 \\
cases & 6 & 8 & 0.33 & 0.56 \\
\hline
\end{tabular}


The BXXXD was produced from decoction of a mixture of pinellia (15 g), Scutellaria baicalensis $(9 \mathrm{~g})$, dried ginger $(9 \mathrm{~g})$, ginseng $(9 \mathrm{~g})$, roasted licorice $(9 \mathrm{~g})$, coptis $(3 \mathrm{~g})$, and 4 jujubes in 1 liter of water [11-13]. The decoction was stopped when $300 \mathrm{~mL}$ of liquid remained in the flask. The patients were given the decoction at a dose of $100 \mathrm{~mL}$ three times daily for seven consecutive days.

\section{Treatment indicators}

Treatment effectiveness, incidence of adverse reactions, extent of recurrence at 1,2 , and 3 months after treatment, gastrointestinal dysfunction scores after 1 week of treatment, QLI scores, frequencies of flatulence and defecation within $48 \mathrm{~h}$, number of bowel rumblings, and levels of gastrin and CCK were determined and compared between the two groups of patients.

\section{Treatment outcome}

Treatment outcome was classified as markedly effective, effective or ineffective. If the clinical manifestations of sepsis and gastrointestinal dysfunction disappeared completely, and the patients had no adverse reactions, the outcome was markedly effective. If most of the clinical manifestations disappeared, and there were no obvious adverse reactions, the outcome was classified as effective.

However, if the clinical manifestations of the patient did not show any obvious sign of disappearance, and serious adverse reactions occurred, the outcome was deemed ineffective.

\section{Gastrointestinal symptom}

The gastrointestinal symptom rating scale (GSRS) had a total score of 112 points. The lower the score, the better the condition. The evaluation criteria included 16 items such as abdominal pain, constipation, diarrhea, nausea, and bowel rumblings. Each item had a total score of 7 points. 'No symptom' was scored 1 point, while very 'severe symptom' was scored 7 points.

\section{QLI}

The QLI standards involved scoring standards for daily activities such as work and life, and interpersonal relationships. Each standard had a full score of 10 points. The higher the score, the better the patient's quality of life, and vice versa. The effect of gastrin is opposite to that of CCK. Gastrin is a hormone that accelerates gastric emptying and enhances digestion, while CCK inhibits gastric secretion and gastric motility.

\section{Statistical analysis}

Data processing and analysis were conducted using SPSS20.0, while GraphPad Prism 7 (GraphPad Software, San Diego, USA) was employed for graphics. The results obtained in this research comprised count data and measurement data. Measurement data are expressed as mean $\pm S D$, and they were statistically analyzed with Students' $t$-test. Count data are presented as numbers and percentages [n (\%)], and were compared with chi squared $\left[\mathrm{x}^{2}\right]$ test. Values of $p<0.05$ were taken as indicative of statistically significant differences.

\section{RESULTS}

\section{Treatment efficacy}

Results in Table 2 indicate higher treatment effectiveness in the study group than in the control group $(p<0.05)$.

\section{Incidence of adverse reactions}

From the results of Figure 2, it is apparent that the study group had a significantly lower incidence of adverse reactions than the control group $(p<0.05)$.

\section{Incidence of recurrence after treatment}

Compared to the control group, treatment with BXXXD + acupuncture significantly decreased the incidence of disease reoccurrence at 1 month $\left(0 \%\right.$ vs $\left.8 \%, X^{2}=4.17, p=0.04\right), 2$ months $(2 \%$ vs $\left.14 \%, X^{2}=4.89, p=0.02\right)$, and 3 months $(2 \%$ vs $18 \%, X^{2}=7.11, p=0.008$ ) after treatment (all $p<0.05)$, as shown in Figure 1 .

Table 2: Comparison of treatment efficacy between the two groups

\begin{tabular}{lcccc}
\hline Group & $\begin{array}{c}\text { markedly } \\
\text { effective }\end{array}$ & effective & ineffective & Total effective rate \\
\hline study & 42 & 7 & 1 & $49(98 \%)$ \\
Control & 30 & 11 & 9 & $41(82 \%)$ \\
$X^{2}$ & & & & 7.110 \\
$P$-value & & & 0.008 \\
\hline
\end{tabular}


Table 3: Comparison of incidence of adverse reactions between the two groups

\begin{tabular}{lccccc}
\hline Group & nausea & bad breath & peculiar urine & $\begin{array}{c}\text { multiple organ } \\
\text { dysfunction }\end{array}$ & Total incidence \\
\hline study & 2 & 1 & 0 & 0 & $3(6 \%)$ \\
Control & 2 & 4 & 4 & 3 & $13(26 \%)$ \\
$X^{2}$ & & & & & 7.440 \\
$P$-value & & & & 0.006 \\
\hline
\end{tabular}

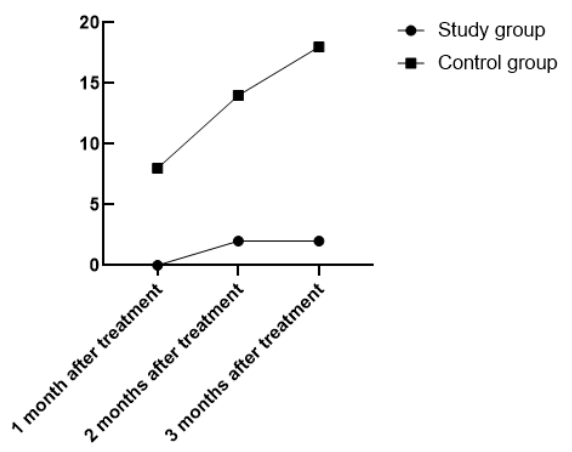

Figure 1: Comparison of incidence of recurrence between the two groups at 1 month, 2 months, and 3 months post-treatment

\section{Gastrointestinal dysfunction scores and QLI scores after 1 week of treatment}

There was lower gastrointestinal dysfunction score in the study group $(55.26 \pm 7.31)$ than in the control group $(69.8 \pm 7.50),(t=9.60, p<$ $0.001)$; QLI score was higher in the study group $(72.99 \pm 8.64)$ than in the control group $(63.57 \pm$ 8.03), $(\mathrm{t}=5.65, p<0.001)$, as shown in Figure 2.

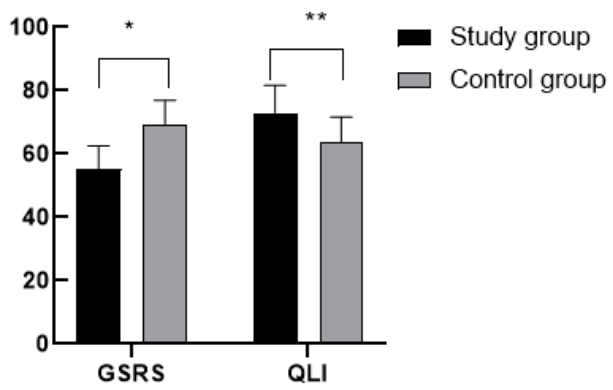

Figure 2: Comparison of gastrointestinal dysfunction scores and QLI scores between the two groups after 1 week of treatment

Frequencies of flatulence and defecation, and number of bowel rumblings within 48 hours

The results in Table 4 reveal that the combination of BXXXD and acupuncture yielded beneficial outcome in terms of frequencies of flatulence and defecation and the number of bowel rumblings in the study group, when compared to the control group $(p<0.05)$.

Table 4: Comparison of frequencies of flatulence and defecation, and number of intestinal rumblings in the two groups within $48 \mathrm{~h}(\mathrm{n})$

\begin{tabular}{lccc}
\hline Group & $\begin{array}{c}\text { Flatulence } \\
(\mathbf{n} / \mathbf{4 8 h})\end{array}$ & $\begin{array}{c}\text { Defecation } \\
(\mathbf{n} / \mathbf{4 8 h})\end{array}$ & $\begin{array}{c}\text { Bowel } \\
\text { rumblings } \\
(\mathbf{n} / \mathbf{m i n})\end{array}$ \\
\hline study & $5.68 \pm 1.13$ & $3.25 \pm 0.11$ & $4.06 \pm 0.81$ \\
Control & $4.30 \pm 0.96$ & $2.00 \pm 0.07$ & $3.00 \pm 0.62$ \\
$t$ & 6.58 & 67.79 & 7.35 \\
$P$-value & $<0.001$ & $<0.001$ & $<0.001$ \\
\hline
\end{tabular}

\section{Levels of gastrin and CCK}

After 1 week of treatment, gastrin level (83.20 \pm $9.91 \mathrm{ng} / \mathrm{L}$ ) of the study group was significantly higher than that of the control group (72.54 \pm $8.86 \mathrm{ng} / \mathrm{L})(\mathrm{t}=5.67, p<0.001)$; CCK level in the study group $(441.46 \pm 51.07 \mathrm{ng} / \mathrm{L})$ was lower than that in the control group $(519.68 \pm 53.34 \mathrm{ng} / \mathrm{L})$, (t $=7.49, p<0.001)$, as shown in Figure 3 .

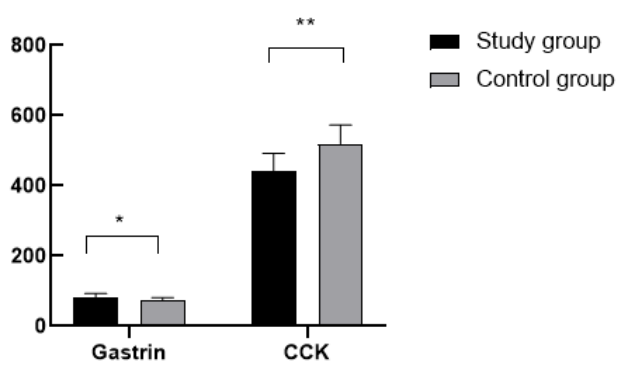

Figure 3: Comparison of levels of gastrin and CCK between the two groups

\section{DISCUSSION}

Sepsis, a major contributing factor to the death of ICU patients, is characterized by fever, shock, and hypotension [14-16]. This infectious disease may also give rise to organ failure or dysfunction. It has been reported that increased levels of inflammatory factors are triggered by different types of bacteria in the gastrointestinal tract during gastrointestinal dysfunction, resulting in a high risk of sepsis [17-19]. Consequently, simultaneous treatment is indispensable for patients with sepsis and gastrointestinal 
dysfunction so as to suppress the causative relationship between these two diseases [20-22].

Traditional Chinese medicine is an effective treatment method for improvement of gastrointestinal environment and function, while relieving clinical manifestations. In this respect, the most frequently used Traditional Chinese methods are acupuncture and Chinese medicine decoction. In particular, $\mathrm{BXXXD}$ is a traditional Chinese medicine formula used for the treatment of various types of acute and chronic gastroenteritis. It is decocted from a mixture of components such as pinellia, astragalus, ginseng, jujube, and other components. It produces promising therapeutic effect against gastrointestinal dysfunction through the combination of cold and warm medicinals and dispersing abdominal mass and resolving accumulation [23-25].

In order to study the effect of application of combination of acupuncture and BXXXD in the treatment of patients with sepsis and gastrointestinal dysfunction, this research matched patients with the two diseases as subjects. Treatment effectiveness, incidence of adverse reactions, recurrence at 1,2 and 3 months after treatment, gastrointestinal dysfunction scores after 1 week of treatment, QLI scores, frequencies of flatulence and defecation within 48 hours, number of bowel rumblings, and levels of gastrin and CCK in the two groups of patients were determined and compared. The results showed that the group treated with $B X X X D$ had better outcomes with respect to treatment effectiveness, QLI scores, frequencies of flatulence and defecation within $48 \mathrm{~h}$, number of bowel sounds, and the level of gastrin, than the control group.

The combination of sepsis and gastrointestinal dysfunction is manifested as constipation, decreased frequency of flatulence, abdominal distension, gastric acid reflux, and weak or nonexistent bowel sounds. Gastrin is a hormone that promotes the secretion of gastric juice and retards the formation of gastric acid. Thus, the secretion of gastrin is crucial in the treatment of gastric reflux patients since it substantially alleviates the manifestations of gastric reflux. In addition, the quality of life of patients with sepsis and gastrointestinal dysfunction is impaired to a certain extent. Consequently, patients' recovery can be determined by the assessment of quality of life. In this study, treatment of patients with sepsis and gastrointestinal dysfunction using combination of acupuncture and BXXXD resulted in an apparent promotion of the quality of life and disappearance of clinical manifestations of the diseases. There was strong evidence of lower incidence of adverse reactions, reduced incidence of recurrence at 1 month, 2 months, and 3 months after treatment, lower gastrointestinal dysfunction scores and CCK levels after 1 week of treatment in the study group, when compared with the control group. After treatment, failure to adopt good dietary habits, or incomplete initial treatment may delay the patients' improvement. In light of this, the curative effects of the two treatment methods were analyzed by following up on the incidence of recurrence at 3 months after treatment.

Gastrointestinal dysfunction scores are mainly used to determine the degree of gastrointestinal disorders in patients through detection and evaluation of gastrointestinal tract conditions, so as to facilitate developments in treatment and the use of drugs. Similar results have also been proposed in a previous study which found that the comprehensive treatment of sepsis complicated with gastrointestinal dysfunction using combination of acupuncture and traditional Chinese medicine decoction resulted in enhanced treatment effect, improved clinical manifestations of patients, and decreased probability of multiple organ dysfunction [26].

\section{Limitations of the study}

The current study has several limitations, such as a small sample size and absence of a longterm follow-up. As a result, the findings should be interpreted with cautions, and long-term data and more participants will be needed to obtain more accurate data.

\section{CONCLUSION}

The combination of acupuncture with BXXXD produces a promising therapeutic effect in sepsis patients with gastrointestinal dysfunction, by reducing clinical symptoms, promoting recovery, and elevating the quality of life and the survival of patients.

\section{DECLARATIONS}

\section{Conflict of interest}

No conflict of interest is associated with this work.

\section{Contribution of authors}

We declare that this work was done by the authors named in this article and all liabilities 
pertaining to claims relating to the content of this article will be borne by the authors.

\section{Open Access}

This is an Open Access article that uses a funding model which does not charge readers or their institutions for access and distributed under the terms of the Creative Commons Attribution License (http://creativecommons.org/licenses/by/ 4.0) and the Budapest Open Access Initiative (http://www.budapestopenaccessinitiative.org/rea d), which permit unrestricted use, distribution, and reproduction in any medium, provided the original work is properly credited.

\section{REFERENCES}

1. Sanchez-Pino MD, Dean MJ, Ochoa AC. Myeloid-derived suppressor cells (MDSC): When good intentions go awry. Cell Immunol. 2021; 362:104302.

2. Li Q, Zheng S, Zhou PY, Xiao Z, Wang R, Li J. The diagnostic accuracy of procalcitonin in infectious patients after cardiac surgery: a systematic review and meta-analysis. J Cardiovasc Med (Hagerstown). 2021;22(4):305-312.

3. Onawola AM. Early Recognition and Management of Sepsis in the Elderly: A Case Study. Crit Care Nurs Q. 2021;44(2):175-181.

4. Cooper PB, Hughes BJ, Verghese GM, Just JS, Markham AJ. Implementation of an Automated Sepsis Screening Tool in a Community Hospital Setting. J Nurs Care Qual. 2021;36(2):132-136.

5. Wang Y, Sun F, Hong G, Lu Z. Thyroid hormone levels as a predictor marker predict the prognosis of patients with sepsis. Am J Emerg Med. 2021; 45:42-47.

6. Cortegiani A, Grasselli G, Meessen J, Moscarelli A, Ippolito M, Turvani F, Bonenti CM, Romagnoli S, Volta CA, Bellani G, Giarratano A, Latini R, Pesenti A, Caironi $P$. Albumin replacement therapy in immunocompromised patients with sepsis - Secondary analysis of the ALBIOS trial. J Crit Care. 2021; 63:8391.

7. Ma X, Zhu G, Jiao $T$, Shao $F$. Effects of circular RNA Ttc3/miR-148a/Rcan2 axis on inflammation and oxidative stress in rats with acute kidney injury induced by sepsis. Life Sci. 2021; 272:119233.

8. Matsuura $H$, Matsumoto $H$, Okuzaki D, Shimizu K, Ogura $H$, Ebihara $T$, Matsubara $T$, Hirano SI, Shimazu $T$. Hydrogen Gas Therapy Attenuates Inflammatory Pathway Signaling in Septic Mice. J Surg Res. 2021; 263:63-70.

9. Li X, Li R, Gong Q, Shi D, Song L, Song Y. Circular RNA circVMA21 ameliorates lipopolysaccharide (LPS)induced acute kidney injury by targeting the miR-199a5p/NRP1 axis in sepsis. Biochem Biophys Res Commun. 2021; 548:174-181.
10. Department of Health, Education, and Welfare; National Commission for the Protection of Human Subjects of Biomedical and Behavioral Research. The Belmont Report. Ethical principles and guidelines for the protection of human subjects of research. J Am Coll Dent 2014; 81: 4-13.

11. Coombs DM, Kwiecien GJ, Koval C, Eghtesad B, Papay FA, Siemionow M, Gastman BR. Successful Treatment of Life-Threatening COVID-19 Infection in a Face Transplant Recipient. Ann Plast Surg. 2021;87(1):105106.

12. Wang Z, Chen W, Li Y, Zhang S, Lou H, Lu X, Fan X. Reduning injection and its effective constituent luteoloside protect against sepsis partly via inhibition of HMGB1/TLR4/NF-KB/MAPKs signaling pathways. J Ethnopharmacol. 2021; 270:113783.

13. Luu DT, Duc NM, My TT, Ly TT, Bang LV, Lenh BV. Extraperitoneal bladder perforation secondary to transurethral resection of bladder tumor. Radiol Case Rep. 2021;16(4):811-814.

14. Chen $D D$, Wang HW, Cai XJ. Transcription factor Sp1 ameliorates sepsis-induced myocardial injury via ZFAS1/Notch signaling in H9C2 cells. Cytokine. 2021; 140:155426.

15. Khosrojerdi A, Soudi S, Zavaran Hosseini A, Ghaffari Khaligh S, Hashemi SM. Imipenem alters systemic and liver inflammatory responses in CLP- induced sepsis mice in a dose-dependent manner. Int Immunopharmacol. 2021; 93:107421.

16. Hu S, Pi Q, Luo M, Cheng Z, Liang X, Luo S, Xia Y. Contribution of the NLRP3/LL-1 $\beta$ axis to impaired vasodilation in sepsis through facilitation of eNOS proteolysis and the protective role of melatonin. Int Immunopharmacol. 2021; 93:107388.

17. Basak JM, Ferreiro A, Cohen LS, Sheehan PW, Nadarajah CJ, Kanan MF, Sukhum KV, Dantas G, Musiek ES. Bacterial sepsis increases hippocampal fibrillar amyloid plaque load and neuroinflammation in a mouse model of Alzheimer's disease. Neurobiol Dis. 2021; 152:105292.

18. Park J, Ahn S, Lee S, Song J, Moon S, Kim J, Cho H. Association of ischemia modified albumin with mortality in qSOFA positive sepsis patients by sepsis-3 in the emergency department. Am J Emerg Med. 2021; 44:7277.

19. Li H, Chen Y, Hu Z, Jiang J, Li R, Qiu Q, Ye J. Effectiveness of acupuncture for the recovery of gastrointestinal function of patients with gastric cancer in the postoperative period: A protocol for systematic review and meta-analysis. Medicine (Baltimore). 2021 ;100(7): e23950.

20. Sin SH, Wu J, Kang Y, Yip KHK, Kong NS, Wan $\mathrm{H}, \mathrm{Ng}$ $B F L$, Chen $H$. Efficacy of modified Banxia Xiexin decoction in the management of Wei-Pi syndrome (postprandial distress syndrome): study protocol for a randomized, waitlist-controlled trial. Trials. 2021;22(1):135.

Trop J Pharm Res, September 2021; 20(9): 1988 
21. Sakakibara R. Gastrointestinal dysfunction in movement disorders. Neurol Sci. 2021;42(4):1355-1365.

22. Rahayatri TH, Pramudito BC, Soedibyo S. Vaginal reconstruction using ileum segment and posterior sagittal anorectoplasty in a patient with MayerRokitansky-Küster-Hauser syndrome with anorectal malformations: A case report. Int J Surg Case Rep. 2021; 79:76-83.

23. Zhu W, Li J, Shen H. Banxia Xiexin Decoction in the treatment of $\mathrm{Hp}$-associated peptic ulcer: A protocol for systematic review and meta-analysis. Medicine (Baltimore). 2021 ;100(2): e24105.

24. Shi JW, Li ZZ, Wu JS, Jin WY, Chang $X Y$, Sun $H$, Dong $L$, Jiang $Z P$, Shi $Y$. Identification of the bioactive components of Banxia Xiexin Decoction that protect against CPT-11-induced intestinal toxicity via UPLCbased spectrum-effect relationship analyses. J Ethnopharmacol. 2021; 266:113421.

25. Huang C, Li X, Wu L, Wu G, Wang P, Peng Y, Huang S, Yang Z, Dai W, Ge L, Lyu Y, Wang L, Zhang A. The effect of different dietary structure on gastrointestinal dysfunction in children with cerebral palsy and epilepsy based on gut microbiota. Brain Dev. 2021;43(2):192199.

26. Zhang J, Huang J, Chang WD, Zhang XZ, Zhang J, Yang G, Li J. Clinical study on the treatment of sepsis gastrointestinal dysfunction by TCM comprehensive therapy. New Chin Med,2019;51(06):154-158. 